\section{Durability and Efficiency of Recycled Multilayer Plastic Covering in the Production of Greenhouse- grown Tomatoes}

\author{
M.A. Kasrawi ${ }^{1}$, N. Khraishi², \\ and $Y$. Tabaza²
}

Additional index words. physical properties, Lycopersicon esculentum, virgin monolayer plastic, pollution

Summary. A greenhouse experiment was conducted over two growing sea sons to study the physical and mechanical properties of a recycled multilayer plastic cover and its effect on the production of greenhouse-grown tomatoes. T wo experimental greenhouses were constructed, one covered with recycled multilayer film and the other with conventional virgin monolayer film. The air temperature under both covers was similar; the soil temperature in the recycled multilayer house was a few degrees lower in the afternoon hours to midnight than in the virgin monolayer house. The recycled multilayer film retained its strength and elasticity over a useful service life of 7 months (one growing season), after which severe degradation occurred as manifested by a $50 \%$ loss of elongation at break. D uring the useful lifetime of the film, haziness, light scattering, and light transmission of the recycled film was similar to the conventional film. The thermal analysis of the recycled film revealed a low stability against thermo-oxidative degradation and the infrared analysis indicated the presence of a measurable amount of degradation products, mainly carbonyl groups, in the recycled film in comparison with conventional film. During the useful lifetime of recycled film, yield compo-

\footnotetext{
${ }^{1} \mathrm{D}$ epartment of Plant Production, $U$ niversity of J ordan, A mman, Jordan.

${ }^{2} \mathrm{R}$ oyal Scientific Society, A mman, Jordan.

The cost of publishing thispaper wasdefrayed in part by the payment of page charges. U nder postal regulations, this paper therefore must be her eby marked advertisement solely to indicate thisfact.
}

nents of the tomato crop were identical to the conventional film in both growing seasons. In conclusion, waste plastic recycling offers an attractive solution to nuisance environmental problems. H owever, the useful lifetime of recycled films needs to be improved.

$\mathrm{n}$ the past 2 decades, expansion of high-valuehorticultural cropsproduction has been associated with an increase in the use of plastic. Plastic greenhousesand high tunnelsnow cover $\approx 200,000$ ha, worldwide (Wittwer, 1993). Plastic houses in Jordan occupied $>1170$ ha in 1992. The use of protected agriculture in J ordan has resulted in the accumulation of $\approx 5800$ tons of waste plastic films per year (Ali et al., 1990). D isposal of these waste plastics hasbeen accomplished by burning or dumping in landfills. Asenvironmental concerns about plastic disposal continue to grow, more pressure is applied by various groups to develop alternative safe disposal technologies (Ennis, 1987). Although the current plastic revolution has increased productivity and improved quality of horticultural crops, problems of plastic disposal (Brown and Splittstoesser, 1991) and the high cost of plastic films may limit the use of plastic. Recycling of plastics could bea possible approach to reducing "plastic pollution," alleviating disposal problems (Glenn, 1990; Leaversuch, 1991) and offering plastic at lower prices (K hraishi, 1993).

The quality of a greenhouse cover has a major influence on crop production. Strength, consistency, durability, manufacturing quality, transmission of solar radiation, haziness, and energy conservation should be considered in selecting greenhouse covers. The objectives herewereto measurethe physical and mechanical properties of a recycled multilayer plastic film and to study the effects of recycled multilayer plastic film cover on the production of greenhouse-grown tomatoes.

\section{$M$ aterials and methods}

$D$ iscarded greenhouse films were collected from the center of the J ordan Valley and treated via sequential steps until regenerated granules were obtained using the facilities of the Plastics Research L aboratory of the R oyal Scientific Society (RSS), Amman, Jordan. The recycling steps included collection, coarse size reduction, washing, drying, fine size reduction, and pelletizing to regenerated pellets. The multilayered covers then were coextruded from theregenerated pelletsbyan Egyptian company. The monolayer film was composed of low-density polyethylene (LDPE) and the recycled multilayer film was composed of LDPE, linear low-density polyethylene (LLDPE), ultraviolet stabilizer, and thewasteplastic material. M ore details on the composition and manufacturing of recycled multilayer film werereported in K hraishi (1993). The recycled multilayer film was $15 \%$ thinner than the conventional virgin monolayer film.

The experiment was carried out on a calcareous sandy loam soil at the J ordan U niv. Experimental Station in the J ordan V alley during the 1991-92 and 1992-93 growing seasons. Two $50 \times 9$-m greenhouses were used. 0 ne house was covered with the recycled multilayer film (recycled material), whereas the other house used virgin monolayer conventional film. The tomato cultivar Claudia RAF was used. I dentical soil preparation was made in each greenhouse and the soil was fumigated with methyl bromide. I n each greenhouse, eight raised beds were formed, each $20 \mathrm{~cm}$ high, $60 \mathrm{~cm}$ wide, and $100 \mathrm{~cm}$ from center to center. $D$ rip irrigation and black plastic mulch were applied to the raised beds. Each greenhouse wasdivided into nine equal plots (replications). Each plot consisted of eight, 5-m-long raised beds. The inside environment of the houses was monitored with nine thermocouples at $120 \mathrm{~cm}$ above the soil (one in each plot) along each greenhouse. $A$ 10th thermocouple was inserted 25 $\mathrm{cm}$ deep in the soil at the middle of each greenhouse. All thermocouples were connected to a computer system, model Data-10-Ging (3530 O rion),

Table 1. A verage monthly temperature and day length in the Jordan Valley during 1991-92 and 1992-93.

\begin{tabular}{|c|c|c|c|}
\hline \multirow[b]{2}{*}{ Month } & \multicolumn{2}{|c|}{$\begin{array}{l}\text { Average monthly } \\
\text { temperature (C) }\end{array}$} & \multirow{2}{*}{$\begin{array}{l}\text { Average day } \\
\text { length }(\mathrm{h})\end{array}$} \\
\hline & 1991-92 & 1992-93 & \\
\hline O ctober & 28.6 & 25.6 & 11.4 \\
\hline $\mathrm{N}$ ovember & r 23.5 & 20.9 & 10.5 \\
\hline D ecember & 18.8 & 14.5 & 10.2 \\
\hline J anuary & 14.4 & 12.6 & 10.3 \\
\hline February & 15.8 & 13.6 & 11.1 \\
\hline M arch & 19.2 & 17.5 & 12.0 \\
\hline April & 24.1 & 24.0 & 13.0 \\
\hline M ay & 27.3 & 26.7 & 13.6 \\
\hline
\end{tabular}


to measure and record temperature continuously in both greenhousesand for each growing season. O utside temperatureand average day length during the experiment are reported in Table 1.

Five-week-old tomato seedlings were planted in the raised beds the first week of N ovember

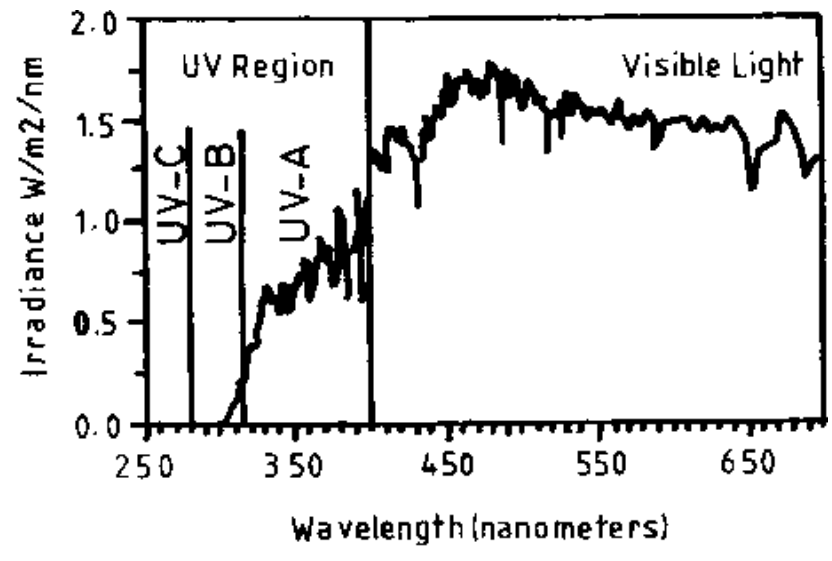

5) Thermal properties (melting point, heat of fusion, and onset of oxidation) using $M$ ettler D SC 30 calorimeter at a heating rate of $10 \mathrm{C} / \mathrm{min}$ (Charkraborty and Scott, 1977).

6) Spectroscopic detection of degradation products by infrared analysis using the Michelson 100 FTIR spectrophotometer (Amin et al., 1975).

7) Absorption of short U $V$ radiation using a Varian DSM -100/ 200 U V-VI S spectrometer. Thistest determines the screening or filtering efficiency of the film (Cordonnier, 1987).

The films also were exposed to

in both 1991 and Fig. 1. The sunlight spectrum.

1992. Plants were set $40 \mathrm{~cm}$ apart at the center of each raised bed. Plants were trained vertically to one stem by removal of axillary shoots as they appeared. Cultural practices, irrigation, fertilization, and spraying for insects and diseases followed standard commercial procedures. Fruits were harvested at the red-ripe stage. $\mathrm{N}$ umbers and weights of fruits were recorded for each plot. A paired comparison test was used for comparing yields.

O ne sample $(30 \times 30 \mathrm{~cm})$ of each monolayer and multilayer films were extracted monthly from N ov. 1991 to J une 1992 from the east side of each greenhouse for laboratory testing. The sampled sectionswere replaced and the greenhouses were repaired promptly. E ach sample was used for five readings. The properties of the extruded films were inspected before and after exposure to outdoor weathering. The facilities of both Royal Scientific Society (Amman, Jordan) and M cGill U niv. (Q uebec, Canada) were used. The following selective tests were conducted:

1) M elt flow index according to ASTM D 1238 using a Frank plastometer at 190C and $5 \mathrm{~kg}$ (Charkraborty and Scott, 1977).

2) Tear-resistance using Schenk Trebel universal testing machine at a speed of $50 \mathrm{~mm} \cdot \mathrm{min}^{-1}$ according to ASTM D-1004. This method tests the resistance of the film to crack propagation (Cordonnier, 1987).

3) T ensilepropertiesusing Schenk Trebel universal testing machine at a speed of $250 \mathrm{~mm} \cdot \mathrm{min}^{-1}$. A $50 \%$ loss of elongation was the criterion of failure or end of service life of the cover (Khraishi and Al-Robaidi, 1991).

4) $\mathrm{H}$ aziness and light transmission using a spherical haze meter according to ASTM D-1003 (Amin et al., 1975).
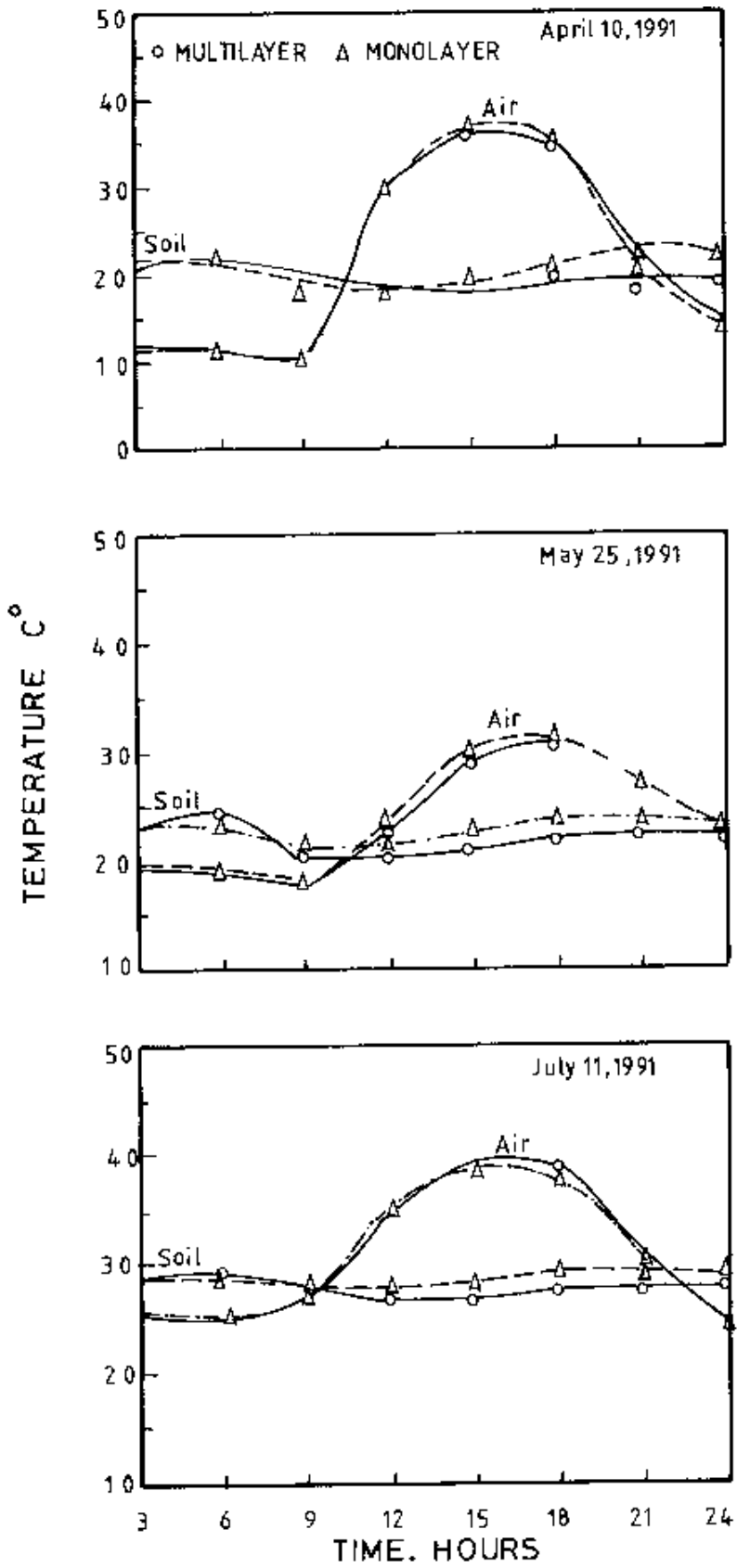

Fig. 2. Temperaturesin greenhousescovered with virgin monolayer and recycled multilayer film. 
ultraviolet radiation from afluorescent lamp type A in aQ - U -V artificial weathering chamber. The weathering cycle was $12 \mathrm{~h}$ of conduction and $12 \mathrm{~h}$ of radiation. The spectral distribution in theultraviolet region of theU VA lamp compared to natural sunlight is shown in Fig 1.

\section{Results and discussion}

Temperatures inside the experimental greenhouseswere recorded over $24 \mathrm{~h}$ for the two growing seasons. Representative samples are shown in Fig. 2. Soil temperature in therecycled multilayer house was a few degrees lower in the afternoon hours to midnight than in the virgin monolayer house, whereas the air temperatures in both houses were very similar. The afternoon cooling suggests that the multilayered cover hasa higher permeability to infrared radiation, which could be attributed in part to the $15 \%$ lower thickness of the multilayer film.

A $50 \%$ loss of elongation is commonly used as the failure criterion of films on the end of the service life of the film. The multilayer cover retained its tensile properties over the first part of the growing season, after which a significant and rapid deterioration in tensile strength was observed (Fig. 3). The monolayer virgin covers showed no variation in the tensile properties over the two growing seasons. The inferior tensilestrength of the recycled multilayer film was compromised by an improved elongation at break over the first growing season due to the optimization of the polymer blend of the bottom layer (Fig. 4). The apparent initial insensitivity to $U V$ radiation is a net effect of competing degradation processes. The photodegradation process in a polymer may involve any or all of thefollowing reactions: $\mathrm{C}$ hainbreaking, resulting in low molecular weight products; cross-linking, resulting in brittleproducts; and formation of low-molecular-weight oxidation products that could be washed away (M ukhopadhyay and Banerjee, 1987). The sharp loss of elongation is a final consequence of those series

Fig. 3. Tensile trength of weathered virgin monolayer and recyded multilayer grenhouse film. of processes involved in the photochemical degradation. (Khraishi and AlRobaidi, 1991).

The thickness of the film plays an important role in the determination of the film service life becausethelight stability decreases significantly with reduced thickness (Cordonnier, 1987). Themultilayer film tested was $15 \%$ thinner than the traditional monolayer film (Table 2). Agricultural Fig. 4. Extensibility of weathered virgin monolayer and recyded films having an average thickness of $150 \mu \mathrm{m}$ commonly last for 1 year in the Jordan Valley, whereas films 180 to $200 \mu \mathrm{m}$ thick last for 2 to 3 years. The tear-resistance of the multilayer film (Fig. 5) was only $2 \%$ less than that of the virgin cover over the 7month weathering period. The inclusion of property modifiers served to improve significantly the impact and tear-strength properties of the recycled waste. The haziness of the multilayer cover showed a similar trend of changewith weathering time, but with higher values than those of virgin monolayer cover (Fig. 6). Both filmsshowed discoloration and loss of transparency after 7 months of exposure. H owever, the multilayer film exhibited a slightly lower light transmission percentage and higher light scatter ( $T$ able $3)$. The lower light transmission in the multilayer film is expected due to the presence of recycled waste with a high gel content. The good scatter diffuses light in such a way that

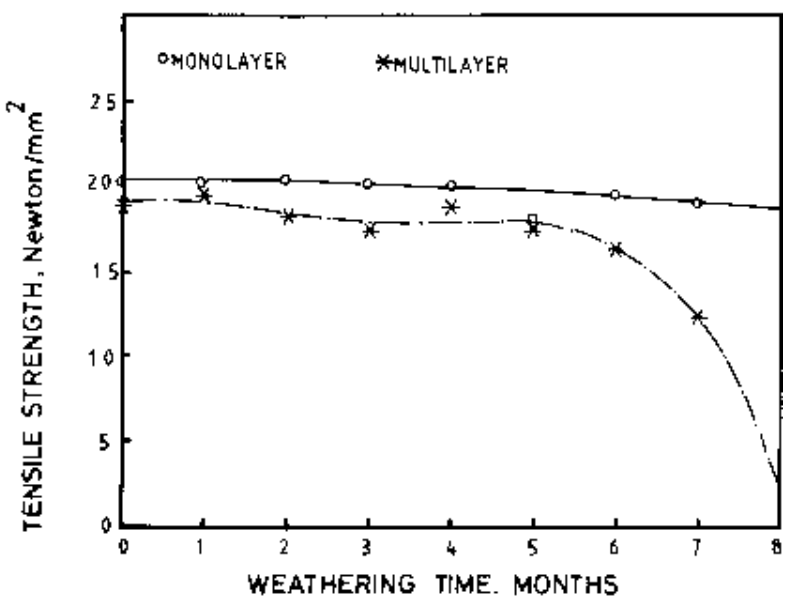

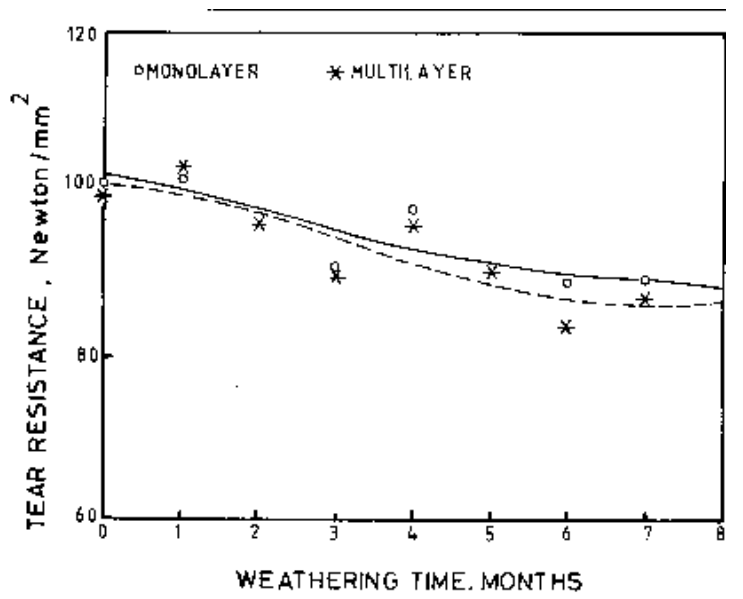

Fig. 5. Tear resistance of weathered virgin monolayer and recycled multilayer grenhousefilm.

plants receive the light with an even intensity from all directions, allowing for uniform growth.

Thethermal analysis of themonolayer and multilayer covers showed no variation in themelting point, whereas the heat of fusion of both covers increased to a maximum value after 5 months of exposure and then declined again (Fig. 7).

The rise in heat of fusion of virgin monolayer film, while maintaining its mechanical strength, reflects an increase in the crystallinity of the film due to an ordering process of the lowmolecular-weight segments enhanced by the absorbed energy. O $\mathrm{n}$ the other hand, the change in the heat of fusion 


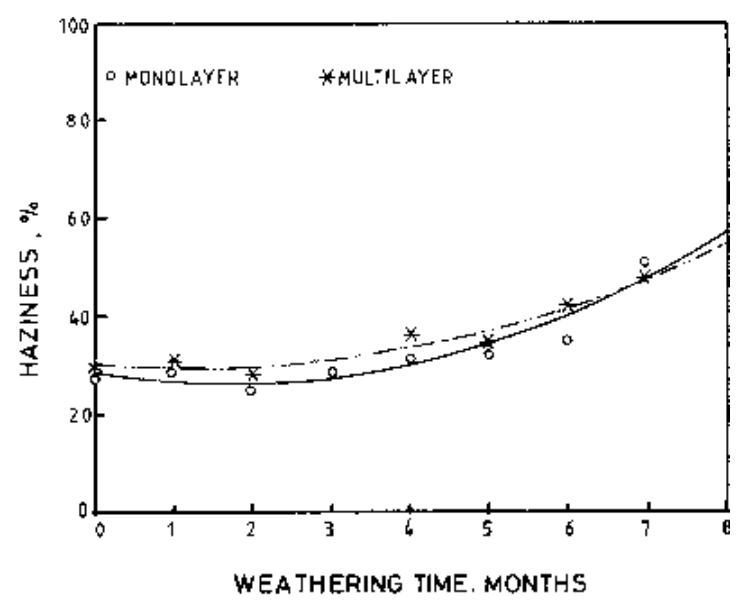

Fig. 6. H azi nes of weathered virgin monolayer and recyded multilayer grenhousfilm.

T able 3. Percentage of light transmision and scatter of weathered monolayer and multilayer films (1991-92).

\begin{tabular}{|c|c|c|c|c|c|c|c|c|}
\hline \multirow[b]{2}{*}{ Variable } & \multicolumn{8}{|c|}{$\mathrm{N}$ atural weathering time (months) } \\
\hline & Nov. & Dec. & Jan. & Feb. & Mar. & Apr. & May & June \\
\hline & \multicolumn{8}{|c|}{ Light transmission (\%) } \\
\hline M onolayer & 89.9 & 88.7 & 89.9 & 88.4 & 88.1 & 87.6 & 85.5 & 84.5 \\
\hline M ultilayer & 88.4 & 86.5 & 85.3 & 86.3 & 86.1 & 85.5 & 86.4 & 83.3 \\
\hline \multirow[t]{2}{*}{ Significance (5\%) } & NS & NS & NS & NS & NS & NS & NS & NS \\
\hline & \multicolumn{8}{|c|}{ Light scatter (\%) } \\
\hline M onolayer & 24.5 & 26.0 & 22.3 & 25.6 & 28.1 & 28.5 & 30.5 & 33.6 \\
\hline M ultilayer & 26.9 & 26.4 & 23.7 & 26.8 & 31.2 & 30.2 & 36.7 & 39.8 \\
\hline Significance (5\%) & NS & NS & NS & NS & NS & NS & S & $\mathrm{S}$ \\
\hline
\end{tabular}

Table 4. Effects of recyded multilayer and virgin monolayer plastic covers on early and total fruit yield and average fruit weight of greenhous-grown tomatoesduring 1991-92 and 199293.

\begin{tabular}{|c|c|c|c|c|}
\hline \multirow[b]{2}{*}{ Plastic film } & \multicolumn{2}{|c|}{ 1991-92 } & \multicolumn{2}{|c|}{ 1992-93 } \\
\hline & E arly & T otal & Early & Tota \\
\hline & \multicolumn{4}{|c|}{ Yield (tons/ ha) } \\
\hline M onolayer & 32.8 & 108.1 & 26.9 & 97.0 \\
\hline M ultilayer & 32.1 & 110.1 & 27.6 & 98.4 \\
\hline Significance ${ }^{z}$ & NS & NS & NS & NS \\
\hline \multicolumn{5}{|c|}{ A verage fruit wt ( $g$ / fruit) } \\
\hline M onolayer & 183 & 158 & 148 & 138 \\
\hline M ultilayer & 177 & 160 & 151 & 139 \\
\hline Significance ${ }^{z}$ & NS & NS & NS & NS \\
\hline
\end{tabular}

zPaired comparison test wasperformed at the $5 \%$ level of significance.

of multilayer film together with the deteriorating properties reflect structural changesdueto photodegradation. Thephotodegradation process of polyethyleneinvolves two competing reactions, namely chain-breaking, resulting in low molecular weight segments, and cross-linking, resulting in an increased molecular weight product. The predominance of either reaction dependson the extent to which the polymer is able to react with oxygen, which is usually present in the amorphous domains of thepolymer. M easurements of the melt flow index (M FI) of the

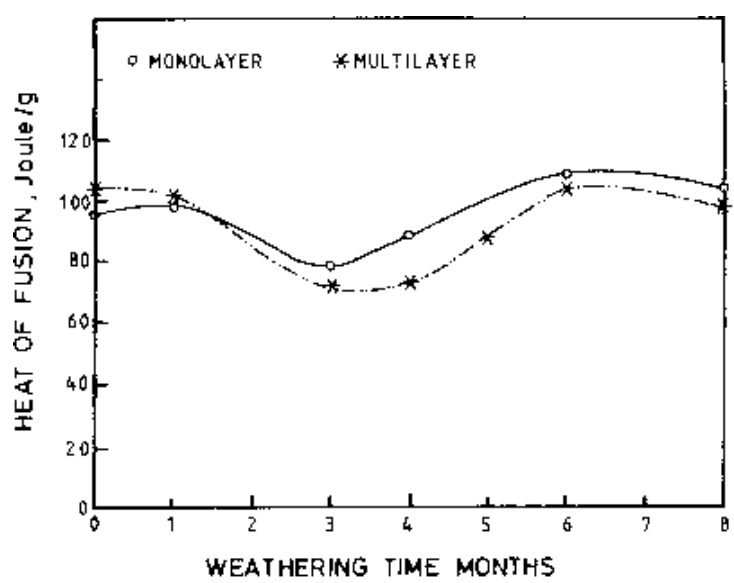

Fig. 7. Heat of fusion of weathered virgin monolayer and recyded multilayer greenhousefilm.

ered multilayered films contained initially a measurableamount of carbonyl at the absorption peak of $1740 \mathrm{~cm}^{-1}$, whereasno peakswere observed in the carbonyl region (1700-1785 $\left.\mathrm{cm}^{-1}\right)$ for the virgin monolayer film. The carbonyl groups in the film containing recycled waste are a main light-absorbing speciesthat initiateand catalyse the photochemical decomposition (Amin et al., 1975). The IR spectrum of monolayer films weathered for 6 months and 15 months, respectively, showed that the virgin plastic film had excellent resistance to weathering, as reflected by the unchanged profile. Attemptsto identify the complexproducts of degradation in the recycled multilayer film did not reveal much information, although significant mechanical deterioration (40\%lossin elongation) was observed. The multilayer spectrum showed a decrease in absorbances at 728 and $1463 \mathrm{~cm}^{-1}$. The peaks at 1247 and $1378 \mathrm{~cm}^{-1}$ also were shifted to 1242 and $1390 \mathrm{~cm}^{-1}$ as a result of structural changes.

Comparison of yields of tomatoes grown in a plastic greenhouse covered by recycled multilayer film with that covered by traditional monolayer film is shown in T ables 4 and 5 . Therewereno differences in early and total tomato yield or average fruit weight between the two covers during either the 199192 or 1992-93 seasons (T able 4). The same monolayer film was used for both seasons; a new multilayer film was used for each season, indicating that theoneseason-old multilayer film was as effectiveastheone- or two-season-old monolayer film in providing the biological requirements of a tomato crop. Although soil temperatures were slightly lower in the greenhouse covered with 
recycled film, the yields were not significantly different. Themultilayer cover hasthepotential to providethebiological requirements of a tomato crop for only one growing season (7 months), whereas the traditional monolayer film is effective as a cover for two or more growing seasons.

The results of this research proved that waste recycling offers an attractive solution to nuisance environmental problems. H owever, subsequent work should be focused on the increase of useful lifetime of the film by controlling the thermo-oxidative degradation.

\section{Literature C ited}

Ali, M., A . Qatarneh, and S. M ehyar. 1990. A marketing study of multilayer polyethylene films in E gypt, J ordan, I raq, Syria and Turkey. Royal Scientific Society, Jordan.

A min M., G. Scott and L. Tillekeratne. 1975. M echanism of the photo-initiation process in polyethylene. European Polymer J. 2:85.

Brown, J.E. and W.E. Splittsoesser.1991. Plasticulture. Disposal problems limit its commercial uses. Proc. N atl. Agr.Plastics Congr. 23:35-38.

CharkrabortyK . and G.Scott. 1977. Effects of the thermal processing on the thermal oxidative and photo-oxidative stabilities of low density polyethylene. European Polymer J. 13:731-737.

Cordonnier, M. 1987. LLDPE and UV aging. Plastics and Rubber Processing and Applic. 8: 23-27.

Ennis, R .S. 1987. Plastigone ${ }^{\text {tw }}$ a new, timecontrolled, photo degradable, plasticmulch film. Proc. 20th $\mathrm{N}$ atl. Agr. Plastics Congr. p. 83-90.

Fontes, M.K. 1973. Controlled environment horticulture in the Arabian $D$ esert at Abu D habi. H ortScience 8(1):13-16

Glen, J. 1990. Curbside recycling reaches 40 millions. Biocycle 3(7):30-37.

K hraishi, N. 1993. M ultilayer polyethylene films (final report). Royal Scientific Society, Amman, Jordan.

K hraishi, N. and A. Al-R obaidi. 1991. E ffect of weathering on $U \mathrm{~V}$ stabilized low density polyethylene film for a multilayer greenhouse cover. Polymer D egradation and Stability 32:105-114.

L eaversuch, R.D . 1991. Chemical recycling brings real versatility to solid-waste management. M odern Plastics 68(7):40-43.

M ukhopadhyay, G. and M. Banerje 1987. Popular Plastics, July. 15.

Wittwer, S.H. 1993. World-wide use of plastics in horticultural production. H ortT echnology 3(1):6-19.

\section{Comparing Objective Quality Attributes of Grapefruit I mported I nto Europe}

\section{L.A. Risse and A.J. Bongers}

Additional index words. Citrusparadis $M$ acf., peel thickness, juice volume, total soluble solids, total acid

Summary. G rapefruit (Citrusparadis $M$ acf.) were sampled biweekly from importers in R otterdam, the N etherlands, from Oct. 1992 through Sept. 1993. For each sample, fruit size, weight, peel thickness, internal pulp color, juice weight, total soluble solids (TSS), and total acid (TA) were measured. Three grapefruit cultivars'M arsh' white, 'Ruby Red', and 'Star R uby' - were sampled from 12 countries of origin. Florida fruit weighed more, had the thinnest peel, the most juice, the lowest TA, and the highest TSS/ T A ratio for all three cultivars compared to all other origins, except for 'R uby Red' grapefruit from C alifornia, which had a lower T A and a higher TSS/ TA ratio. T urkish ' $R u$ by Red' and Spanish 'Star R uby' fruit weighed the least and had the least amount of juice compared to fruit from other origins. T urkish fruit had the highest TA and the lowest T SS/ TA ratio for all three cultivars from all origins. I sraeli 'M arsh' white and 'Star R uby' had the highest TSS. $O$ verall, the internal quality characteristics of Florida fruit was high compared to fruit from other origins.

n 1992, imports of fresh grapefruit into theE uropean Economic Community (EEC) totaled 470,000 metric tons from more than

U.S. D epartment of A griculture, A gricultural R esearch Service, European Marketing R esearch Center, $\mathrm{R}$ otterdam, the $\mathrm{N}$ etherlands.

Mention of a trademark, proprietary product, or vendor doesnot constitutea guarantee or warranty of the product by the U SD A and does not imply its approval to the exclusion of other products of vendors that may also be available. The cost of publishing this paper was defrayed in part by the payment of page charges U nder postal regulations, this paper ther efore must be her eby marked advertisement solely to indicate this fact.
30 countriesof origin (E urostat, 1993). The five leading countries that exported fresh grapefruit to the EEC weretheU nited States, I srael, C yprus, South Africa, and Argentina, which accounts for $\approx 80 \%$ of the total. The next five countries, in descending order (Turkey, H onduras, Cuba, U ruguay, and Swaziland), exported $\approx 12 \%$ of the total. The U nited States and I srael accounted for $\approx 48 \%$ of the total imports into the EEC. However, Cuba's export to theEEC isincreasing rapidly, as is production in Spain and T urkey. The U nited States exported $\approx 98,000$ metric tons to the EEC, mostly from Florida, which exported 7.1 million boxes $(\approx 72,000$ metric tons), or about $18 \%$ of the total imports into the EEC.

External visual quality is very important to most European importers, but internal quality characteristicssuch asjuicevolumeand sweetnessaregaining in importance. Consumers are selecting more products because of better taste and/ or flavor and are shifting gradually from only external quality characteristics as the major buying criteria. Palatability of grapefruit depends on the sweetness and a high ratio of TSS/ TA (H arding, 1952; L ong et al., 1959). In addition to TSS/ TA ratio, juice volume is used as a basis for determining maturity and palatability ( $\mathrm{H}$ arding and Fisher, 1945).

An earlier study was conducted on the variation of three physical and three chemical characteristics related to quality of fresh grapefruit originating from 13 countries and imported into theEEC (H illebrand et al., 1978). That studyindicated that ' $M$ arsh' white grapefruit from Florida had the thinnest peel, highest percent of juice, lowest percent of TA, and highest TSS/ TA ratio compared to fruit from most other origins. Another study conducted on only early season (O ctober/ November) grapefruit arriving from Florida, $\mathrm{C}$ uba, $\mathrm{M}$ exico, and $\mathrm{H}$ onduras into the Rotterdam Fruit Auction showed that Florida fruit compared favorably to fruit from the other origins(H oogendoorn and M iller, 1986). M ost of the grapefruit in that study was 'Ruby Red', and the study was conducted only during a 6-week period in Oct. and Nov. in 1984 and 1985.

The objective of this study was to compare selected physical and chemical characteristics of the grapefruit cul- 